\title{
ROLE OF NEURO-PSYCHLOGICAL TENSION AND FATIGUE IN THE DAILY ACTIVITES OF GENERAL PRACTITION FROM THE STARA ZAGORA REGION
}

\author{
M. Platikanova ${ }^{*}$, V. Slavova ${ }^{2}$, V. Ivanov ${ }^{2}$, S. Alekova ${ }^{3}$ \\ ${ }^{1}$ Department of Hygiene, Epidemiology and Infectious Diseases, Medical Faculty, Trakia University, \\ Stara Zagora, Bulgaria \\ ${ }^{2}$ Department of Neurology, Psychiatry, Medicine of the Disastrous Situations, Medical Faculty, \\ Trakia University, Stara Zagora, Bulgaria \\ ${ }^{3}$ Department of General Medicine and Ophthalmology, Medical Faculty, Trakia University, \\ Stara Zagora, Bulgaria
}

\begin{abstract}
Daily activity of GP is characterized by great neuro-psychological tension and symptoms of fatigue, especially at the end of the workday. An essential prerequisite for this is the intense work and responsibility of physicians. A survey study was conducted using direct mail questionnaire with 10 questions, including questions about the manifestation of neuro-psychological tension effects and fatigue throughout the day of GPs in the Stara Zagora region. The analysis shows that as a result of tension and fatigue, a GP will easily begin carrying out tasks, but the practitioner quickly becomes exhausted. Sometimes fatigue and loss of interest in usual obligations will result in a need of more time for rest and relaxation.

Therefore, in the assessment of the effects of neuro-psychological tension and fatigue on family physicians, it is necessary to apply a modern approach. Based on these statements, it is of utmost importance to develop a system to reduce tension and fatigue's negative effects on GPs.
\end{abstract}

Key words: neuro-psychological tension, GP, fatigue

\section{INTRODUCTION}

The neurotic-psychic tension and the symptoms of tiredness, especially at the end of a working day, are a part of the daily routine of the general practitioner. By the statistics data of the National Association of the General Practitioners in Bulgaria, almost 80 per cent of the family medics suffer of daily stress. One fifth of them are afflicted by a heavy form of stress, while more than half of all general practitioners have bee diagnosed to have the so called Burning Syndrome, which may include emotional exhaustion and state of depression. Although stress is nowadays seen as part of everyday life, a number of authors are of the opinion that it influences the immune system and creates real conditions for developing health problems $(1,2,3)$. A chronically repeated stress condition of a general practitioner (family doctor) can cause

\footnotetext{
*Correspondence to: Magdalena Platikanova, 11 Armeyska Str, 6000 Stara Zagora, Bulgaria, Phone: +35942664240,

E-mail: mplatikanova@abv.bg
}

headache, insomnia, strain and pain in the muscles, disturbances in the stomach and intestine tract, arrhythmia, heartbeat, impeded breathing, and more (4). This may lead to poor atmosphere for work and fall in the quality of work performance.

To a great degree, the neurotic-psychic strain is the result of stress situations in which a general practitioner (family doctor) may fall, like the need to make quick decisions on the spur of the moment, the high demands from the patients and the different organization institutions (The Medicare Insurance Fund, The Regional Health Inspectorate, and others), the changes in the different normative documents, and still other. All these factors lead to symptoms of tiredness. This is why there must be applied a modern approach to assess stress and fatigue.

In this study, we set ourselves the aim to detect the role of the neurotic-psychic tension, as well as, the main signs of tiredness in the day-today work of a general practitioner, and base on 
this study a developed complex of measures for overcoming the causes.

\section{MATERIALS AND METHODS}

A sociological investigation was carried out through direct mail questionnaire form of 10 questions on neurotic-psychic tension and fatigue felt in their daily work by the general practitioners in the Region of Stara Zagora. The data received was processed with the following statistical methods: grouping the data and alternative analysis with the help of MS Office Excel 2003.

\section{RESULTS AND DISCUSSION}

The total number of the general practitioners (family doctors) who completed the questionnaire form was 52. The larger was the age group between 41 and 50, 40 persons (76,92\%), followed by the group of $30-40$ years old, 12 persons $(23.08 \%)$. There were no working persons under 30 years of age over 50 years old among the people inquired. The representation includes 28 women $(53.85 \%)$ и 24 men $(46.15 \%)$. The general practitioners who took part in the inquiry comprise 23 $(44,23 \%)$ of no specialization, $16(30,77 \%)$ of a different specialization, and $13(25 \%)$ of the specialization General Medicine. Those of the inquired general practitioners (family doctors) who had working experience of 6-10 years were $39(75 \%)$.

With $44(84,62 \%)$ of those who responded to the inquiry, the surgeries for first medical aid are situated in towns, and the covered contingent of patients includes all age groups of the two sexes.

In our study, we established the existence of both physical and mental tiredness ensuing neurological-psychic strain. The relative segment of the general practitioners(family doctors) who inform of frequent symptoms of fatigue is 76,93 процента (Figure 1). Almost half of the asked general practitioners (family doctors) $(48,08 \%)$ experience no difficulty at the beginning of an activity at the start of their working day (Figure 2). In the process of working to cope with different tasks, twenty persons of the ones inquired $(38,46 \%)$ inform of signs of tiredness, especially by the end of their working day (Figure 3).

As result of a continuous mental strain, difficulties arising from organization factors in the process of their work, the numerous documents doctors mind, and the communication with the different institutions, the general practitioners announce problems with their concentration.

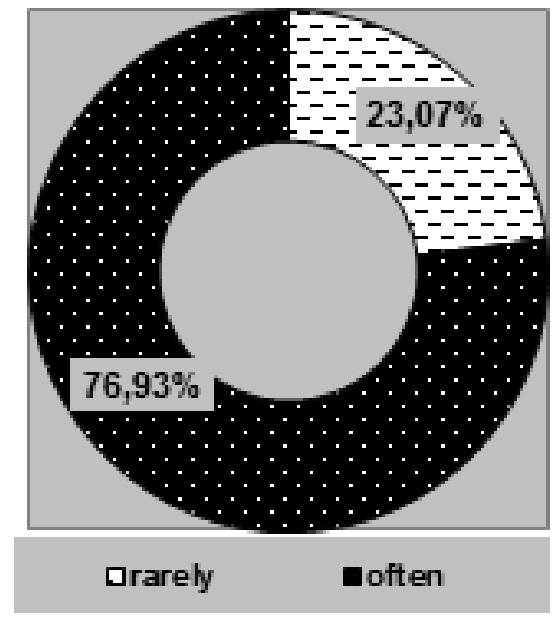

Figure 1. Problems of signs of fatigue (susceptibility to tiredness)

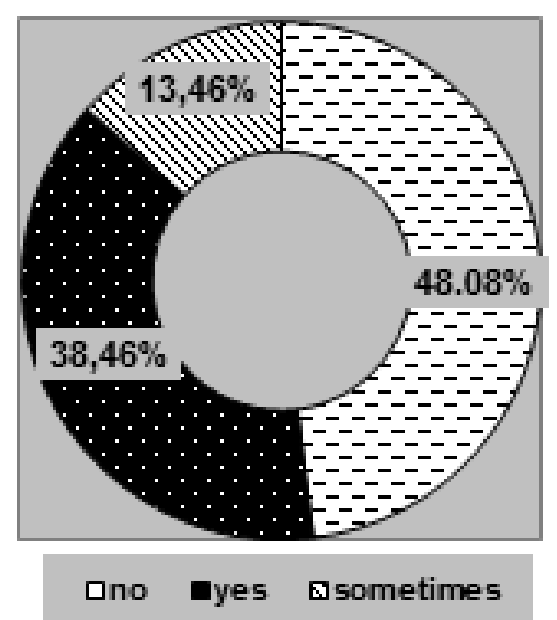

Figure 2. Difficult to start the work day

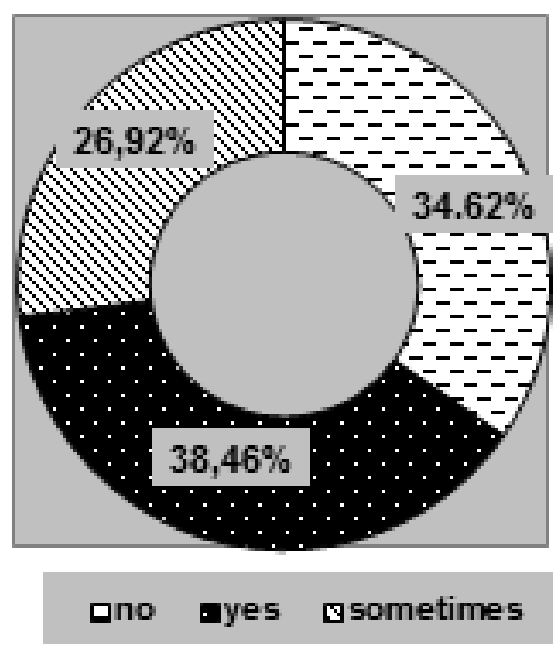

Figure 3. Easily getting tired when dealing with problems

Difficulties with their concentration are often experienced by $26,93 \%$ of the inquired, and rarely experience by $59,61 \%$, sometimes experienced by 13.46 percent (Figure 4). This results in frequent mistakes with $42,31 \%$ of the general practitioners (family doctors) when filling in different administration documents (Figure 5). The inquired doctors who assess their own memory as worse than what is common are $44,24 \%$, as what is usual is to 
$40,38 \%$, the smallest is the percentage of those who answered that their memory is improved as to their usual, 15,38 percent (Figure 6).

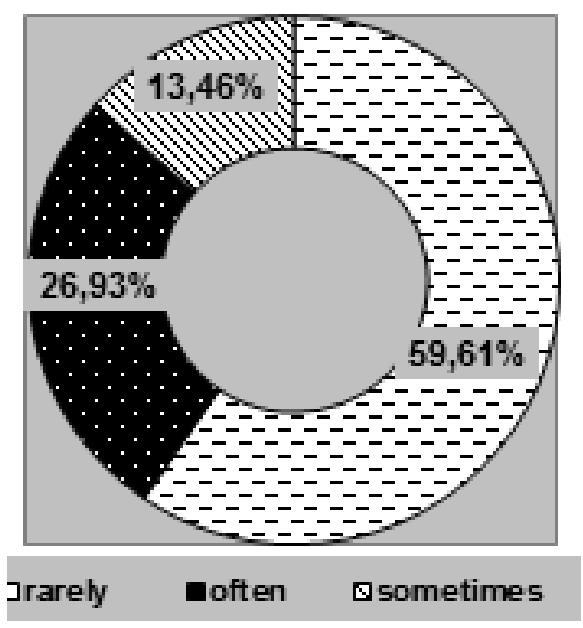

Figure 4. Difficult to concentrate

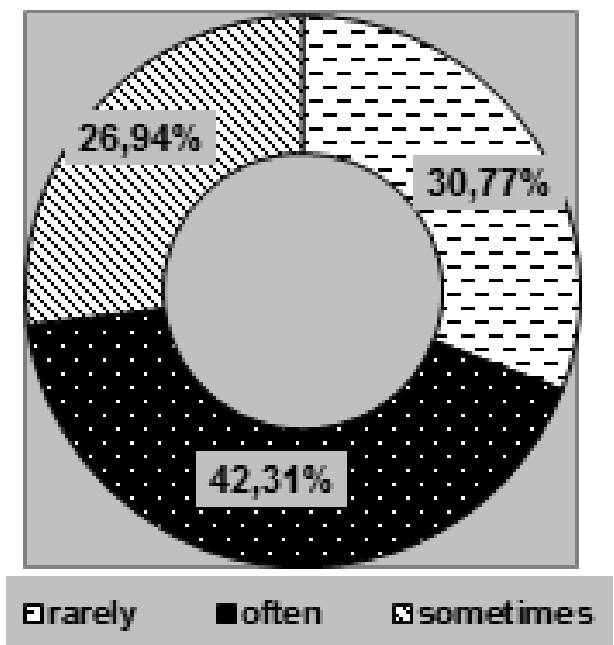

Figure 5. Making mistakes when writing
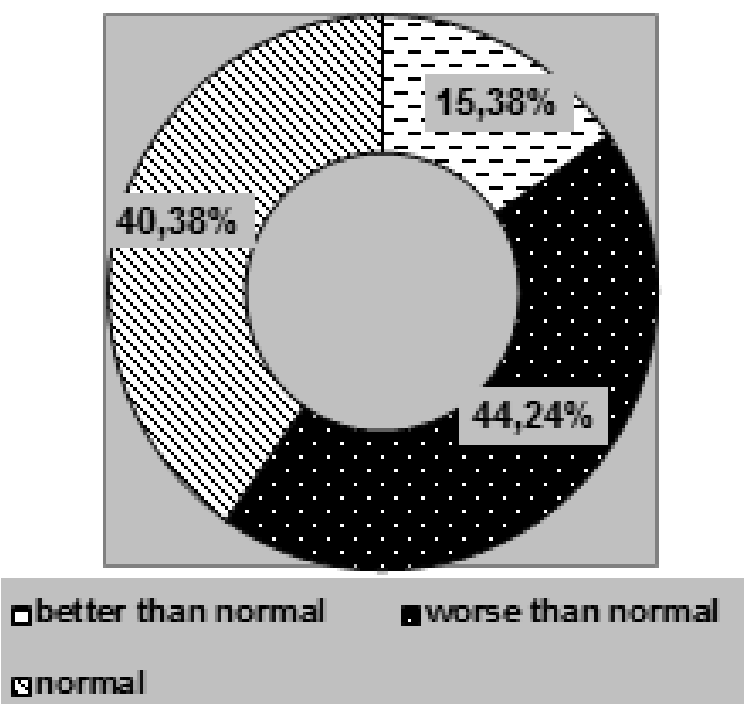

Figure 6. Assessment of memory

Regardless of the big tension in their daily activity, $59,6 \%$ of those who responded to the inquiry rarely feel weakness (Figure 7), $42,31 \%$ tell about rare loss of the energy to work (Figure 8).

\section{PLATIKANOVA M., et al.} Just one general practitioners informs of lost interest in the usual daily duties. The majority of the inquired answer this question with 'sometimes', 63,46 percent (Figure 9).

The percentage of the general practitioners(family doctors) who need more rest and time to relax and restore their strength is big, 76,92\% (Figure 10)

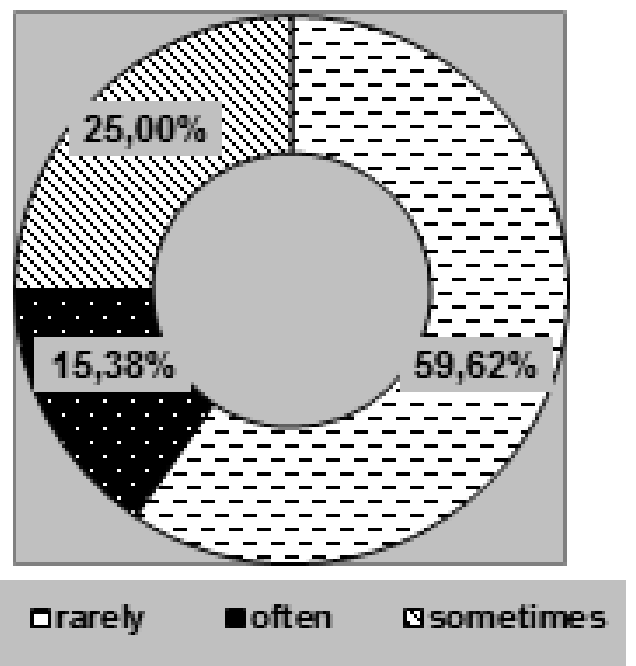

Figure 7. Feeling of weakness

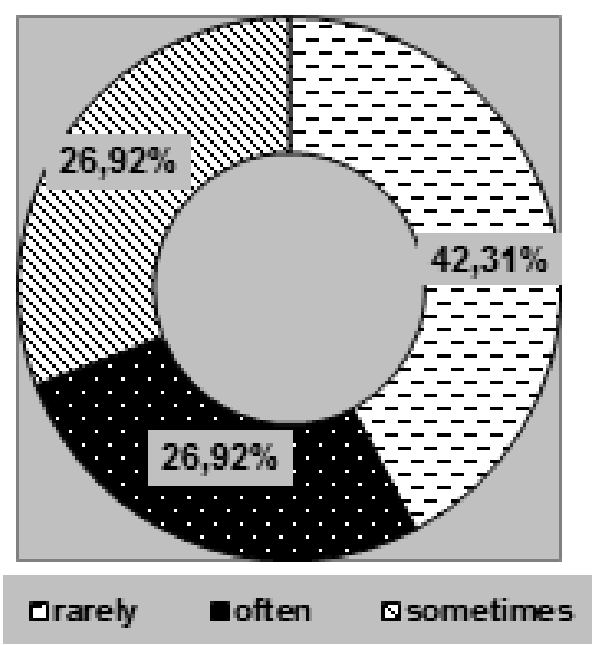

Figure 8. Lacking the energy

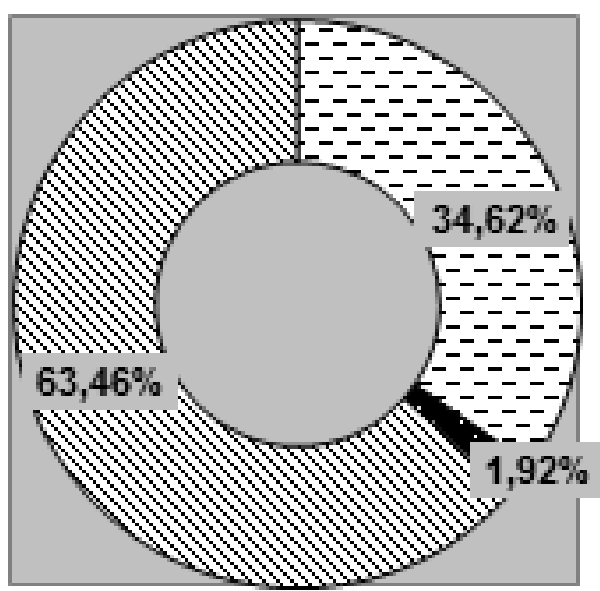

Drarely Doften Bsometimes

Figure 9. Loss of interest in the usual duties 


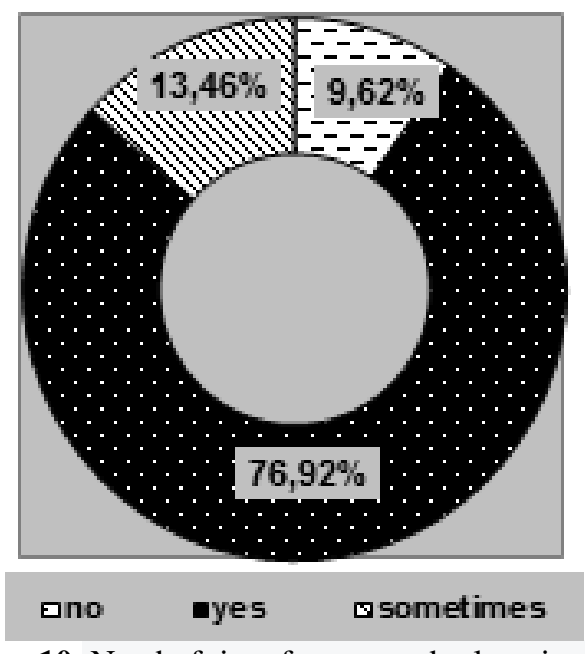

Figure 10. Need of time for rest and relaxation

\section{CONCLUSION}

During their daily work, the general practitioners undergo big neurological-psychic tension which, together with additional external and subjective factors, such life style and ineffective organization and time schedule, may lead to fatigue and serious harm to the health.

Prevention of stress at work places, particularly in the medical profession, is a priority for the member countries of the European Union.

Limiting stress as a risk factor for aggravated psychic condition and health problems is included in the National Health Strategy for the period $2014-2015(5)$. Insusceptibility to stress is connected with the type of person, location of control, and the built-up copying strategies of dealing with it (6).

The strategies of prevention of neurologicalpsychic strain and stress in the case of the general practitioners are three:

1. Removal or modification of the work conditions that cause stress, and decrease in their unfavourable impact on the health and the life of the general practitioners.
PLATIKANOVA M., et al. 2. Adaptation of the changes in the work environment to the individual characteristics of the working general practitioners.

3. Enhancing the individual resistibility to tension and stress, through increase in the consciousness and improved skills to cope with stress, which can be achieved through training in techniques for decreasing the neuroticpsychic tension. (7), promoting a healthy life style, ensuring regular and wholesome rest, and more.

The system of prevention is open and can be changed in accordance with the modern conditions and the arousal of new risk factors.

\section{REFERENCES}

1. Papp, K. K., Stoller, E. P., Sage, P., Aikens, J. E., Owens, J., Avidan, A. et al. The effects of sleep loss and fatigue on residentphysicians: a multi-institutional, mixedmethod study. Acad Med., 79:394-406, 2004.

2. Shaufeli WB., Maassen GH., Bakker AB. and Sixma H.J. Stability and change in burnout: A 10-year follow-up study among primary care physicians. Journal of Occupational and Organizational Psychology, 84 (2):248-267, 2011.

3. Stress at work - short guide. This documents has been and adapted, with permisson from an original published by Health and Safety Executive of Great Britain and available from: http//www.hse.gov.uk/pubns/indg281.pdf

4. Velkova, D. The stress at work, underestimated problem in the work place. Safety and labor medicine, 3:15-16, 2002.

5. National Health Strategy, years $2014-2015$.

6. Jordan J.,Gurr E., Tinline G., Giga S. Faragher B.,Cooper C. Beacons of excellence in stress prevention. 2003.http//www.hse.gov.uk/research/rrpdf/r rl133.pdf

7. Rasheva, M. Dealing with stress and depression. Acad.edition „M. Drinov”, 1719, 2006. 